\title{
Dapsone-resistant leprosy in Addis Ababa: a progress report
}

\author{
TITIA WARNDORFF VAN DIEPEN, SAROJINI \\ PERINGALI AREDATH* \& GENENE MENGISTU \\ All Africa Leprosy Rehabilitation and Training Centre (ALERT) \\ P.O. Box 165, Addis Ababa, Ethiopia
}

Accepted for publication 5 October 1983

\begin{abstract}
Summary Two hundred and twelve lepromatous patients, presenting with suspected dapsone-resistant leprosy in the 5-year period 1973-77, were taken into trial treatment with dapsone. Clinically, $55 \%$ have been proven to be dapsone resistant and the remainder are continuing to respond to full dosage dapsone after 4.5 to 9 years.

This clinical observation contrasts with results of the dapsone-sensitivity studies in mice which demonstrated in $86 \%$ of the 43 patients examined dapsone-resistant bacilli. The relevance of partial dapsone resistance, diagnosed in mouse foot-pad tests, is challenged and a modified definition of dapsone resistance is suggested. The annual incidence of proven dapsone-resistant leprosy over the period $1973-77$ was $1.8 \%$, resulting in a prevalence in 1978 of 119 per 1000 lepromatous cases on register in Addis Ababa.
\end{abstract}

\section{Introduction}

In 1973 the Leprosy Unit of the National Institute for Medical Research in London initiated a Medical Research Council (MRC) Project in the charge of Dr John Pearson at the All Africa Leprosy Rehabilitation and Training Centre (ALERT). All leprosy patients in the Addis Ababa area are started on treatment at this centre and their condition is reviewed, at least half-yearly, at one of its out-patient clinics. All cases with clinical suspicion of dapsone-resistant leprosy were referred to a special clinic for assessment and follow-up, conducted by the MRC. After closure of this project in 1978, the clinic continued its activities with staff of ALERT Hospital until the end of 1982, when it was felt that this special clinic was no longer needed, and its operation discontinued.

The MRC studies, carried out from 1973 to 1978, revealed a higher incidence

* Present Address: Trichur, S.10 Vrindavan Colony, Pattom, Trivandrum 695004, India 
and prevalence of dapsone resistance than has been reported elsewhere. The incidence of suspected dapsone resistance was about $3 \%$ per year and the minimum prevalence of dapsone resistance was found to be 100 per 1000 lepromatous patients in 1978. On the assumption that the majority of relapsed lepromatous cases, despite initial improvement on trial treatment with full dosage of dapsone, would later prove to be resistant, the probable prevalence of dapsone resistance in 1978 was estimated to be 190 per 1000 registered lepromatous cases. $^{1-4}$

Indeed, if all suspected cases would prove to be dapsone resistant, it would ensure, if continued unchecked, that about $30 \%$ of the patients with lepromatous leprosy in the Addis Ababa area would develop dapsone resistance by $1980 .{ }^{1}$ In such a situation the efficacy of dapsone, even in combinations of drugs, would become doubtful. In 1974, however, the treatment policy was changed. The low-dosage schedule of dapsone and discontinuation of dapsone during reactions, introduced 10 years earlier, was abandoned. In spite of the generally low treatment compliance of the Addis Ababa patients, this change of treatment policy might well have had a significant influence on the rate of emergence of dapsone-resistant strains.

Therefore, in 1982, we reviewed the clinical and bacteriological condition of those patients who were suspected of suffering from dapsone-resistant leprosy in the period 1973-77 and were still on trial treatment with a full dose of dapsone. Relevant information on trial patients who changed treatment because of clinical deterioration was obtained from their case notes.

This study has been undertaken primarily to estimate more accurately, with hindsight, the prevalence of dapsone-resistant leprosy in 1978 and the annual incidence in the period 1973-77. An attempt has also been made to study the relationship between the outcome of trial treatment and the results of mouse food-pad tests in the trial patients.

\section{Patients and methods}

Details of the selection of patients for this study, their clinical follow-up and treatment, selection for mouse foot-pad tests and the technique of the mouse studies have been reported. ${ }^{3}$ Between 1973 and 1978, patients started on the trial treatment with full dosage of dapsone (100 mg daily or $375 \mathrm{mg}$ weekly, by injection). Those who were doing well were in the following years continued on this regimen. Assessment, carried out 6 monthly, included clinical drawings and skin smears from the same sites selected at previous assessments, unless new active lesions had appeared. Biopsies for histopathological examination were repeated if the clinical condition had deteriorated. The period of trial treatment was terminated when the patient's condition failed to improve or was aggravated and, therefore, suggested dapsone-resistant leprosy. 
During the period 1973-77 the total intake of relapsed and, therefore, suspected dapsone-resistant lepromatous patients had been 260 out of the 1500 lepromatous cases registered in the Addis Ababa area. About $87 \%$ of these patients presented with a 'classical history' of deterioration despite regular treatment. The remaining $13 \%$ were suspected because of slow improvement, reactions occurring later than usual, a solitary leproma of the eye or a relapse after discontinuation of treatment (group with 'atypical presentation'). By the end of 1977 the percentage of proven dapsone resistance was about equal in both groups. This observation seems to make it unnecessary to maintain the distinction between these two groups.

In 48 out of the total number of 260 patients, treatment with dapsone was discontinued at once because of advanced disease, social reasons or severe complications. Mouse foot-pad (MFP) tests, carried out in $25(52 \%)$, had confirmed dapsone resistance in 24 cases. The remaining 212 patients continued to take dapsone in full dosage, supervised as much as possible. The great majority attended the hospital regularly for treatment and follow-up: only 6 patients $(3 \%)$ have been lost ( 3 each by default and known death).

Another 6 cases were removed from the trial because of mouse foot-pad proven dapsone sensitivity (3) or because they developed severe neuritis requiring change to clofazimine treatment. When the trial was reviewed in 1982, patients had been studied for a minimum of 4.5 years and a maximum of 9 years.

\section{Results}

The results of the review of the 212 patients are presented in Tables 1 and 2. It appears from Table 2 that the majority of the trial cases which proved to be suffering from progressive and, therefore, dapsone-resistant leprosy, did so in the first 3 years of the trial treatment. Thereafter, the probability was around $5 \%$ per year, decreasing to zero after more than 6 years of trial treatment. Forty-five percent of the patients responded to dapsone throughout the trial period.

This prolonged response to dapsone treatment contrasted with the results of the dapsone-sensitivity tests in mice performed in $43(20 \%)$ of the 212 trial patients (see Table 3). In 23 patients the MFP test was carried out at the start of the trial, in 20 at the end. Only 5 (22\%) of the Mycobacterium leprae strains tested at the start, and $6(14 \%)$ of the total number tested, were found to be fully sensitive.

Table 4 presents the relationship between the outcome of trial treatment and the results of MFP tests for those patients tested at the start of the trial. Interestingly, seven resistant strains, including one fully resistant strain, are continuing to respond to a full dose of dapsone in the patients who are still being followed for between 5 and 9 years.

As can be seen from Table 1 the mean annual incidence of suspected and 


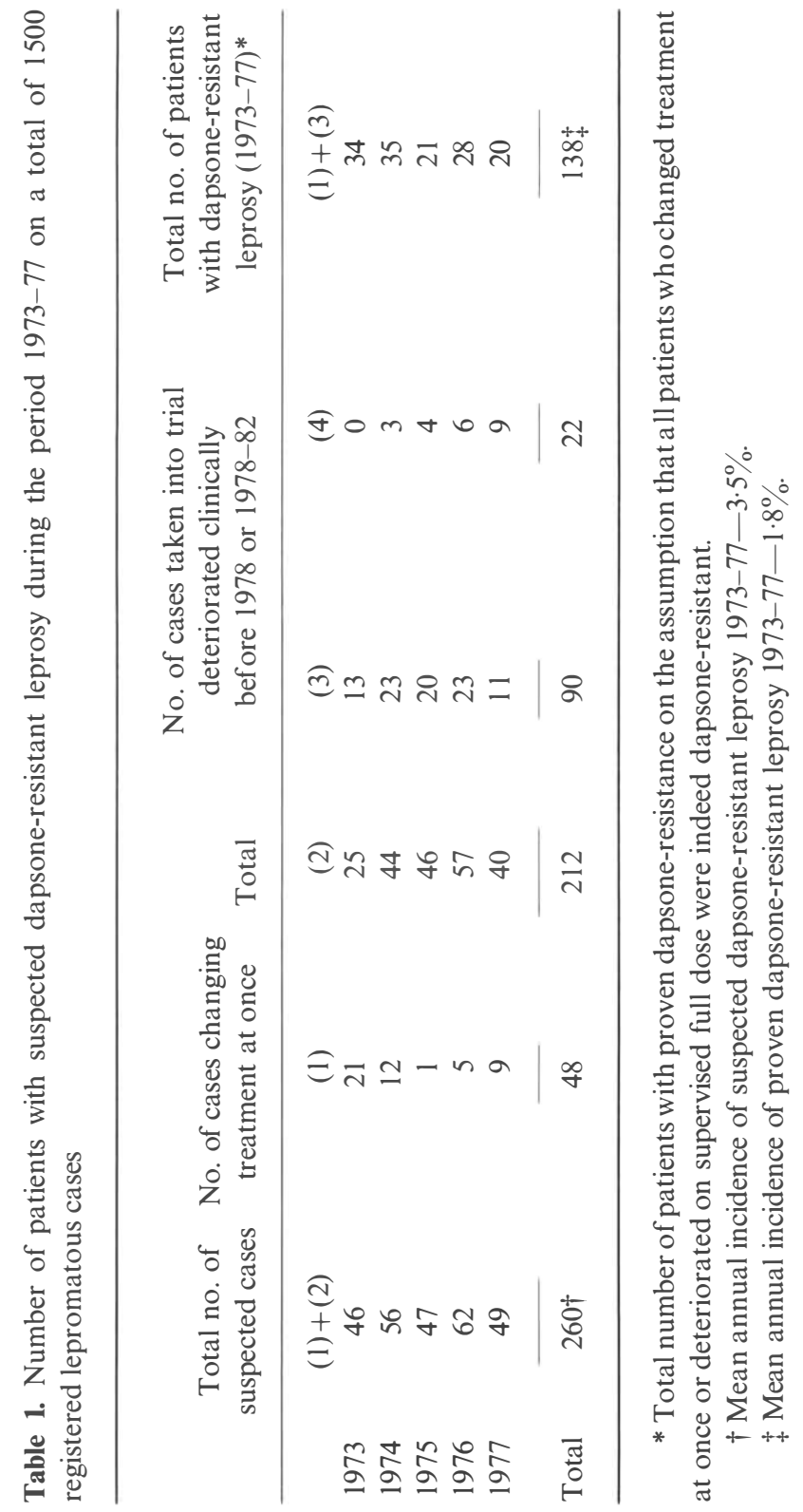


Table 2. Time table of occurrence of dapsone-resistant leprosy in lepromatous patients presenting with a relapse during 1973-77

\begin{tabular}{|c|c|c|c|c|c|c|c|c|}
\hline$T_{x}$ & & $N_{x}$ & $R_{x}$ & $W_{x}$ & & $Q_{x}$ & $P_{x}$ & $L_{x}$ \\
\hline 1 & & 212 & 42 & 3 & $42 / 210 \cdot 5=$ & $0 \cdot 200$ & $0 \cdot 800$ & $80 \cdot 0$ \\
\hline 2 & & 167 & 30 & 3 & $30 / 165 \cdot 5=$ & $0 \cdot 181$ & $0 \cdot 819$ & $65 \cdot 5$ \\
\hline 3 & & 134 & 25 & 1 & $25 / 133 \cdot 5=$ & $0 \cdot 187$ & 0.813 & $53 \cdot 3$ \\
\hline 4 & & 108 & 7 & 3 & $7 / 106 \cdot 5=$ & 0.066 & 0.934 & $49 \cdot 8$ \\
\hline 5 & & 98 & 5 & 1 & $5 / 97 \cdot 5=$ & 0.051 & 0.949 & $47 \cdot 2$ \\
\hline 6 & $92-17=$ & 75 & 3 & 0 & $3 / 75=$ & $0 \cdot 040$ & 0.960 & $45 \cdot 3$ \\
\hline 7 & $72-24=$ & 48 & 0 & 0 & & 0.000 & $1 \cdot 000$ & $45 \cdot 3$ \\
\hline 8 & $48-21=$ & 27 & 0 & 1 & & $0 \cdot 000$ & $1 \cdot 000$ & $45 \cdot 3$ \\
\hline 9 & $26-16=$ & 10 & 0 & 0 & & 0.000 & $1 \cdot 000$ & $45 \cdot 3$ \\
\hline
\end{tabular}

$T_{x}=$ Years since start of trial treatment.

$N_{x}=$ Number of relapsed patients on trial treatment at $T_{x}$.

$R_{x}=$ Number of patients with clinically proven dapsoneresistant leprosy.

$W_{x}=$ Number of patients lost from trial (total of 12).

$Q_{x}=$ Probability of showing clinically dapsone-resistant leprosy in a 1-year period.

$P_{x}=$ Probability of remaining in trial treatment without clinical deterioration during 1 year.

$L_{x}=$ Percentage remaining in trial treatment for $x$ years.

Table 3. Results of mouse foot-pad tests for dapsone sensitivity in 260 patients with suspected dapsone-resistant leprosy

\begin{tabular}{|c|c|c|c|c|}
\hline Degree of sensitivity & & $\begin{array}{l}\text { Patients tested } \\
\text { at start of trial }\end{array}$ & $\begin{array}{c}\text { Patients tested } \\
\text { when deteriorating } \\
\text { on trial treatment }\end{array}$ & $\begin{array}{l}\text { 'No trial' } \\
\text { patients }\end{array}$ \\
\hline Sensitive & & 5 & 1 & 1 \\
\hline Not fully titrated* & & 4 & 10 & 11 \\
\hline Resist $0.0001 \%$ & & 5 & 0 & 6 \\
\hline Resist $0.001 \%$ & & 5 & 3 & 0 \\
\hline \multirow[t]{2}{*}{ Resist $0.01 \%$} & & 4 & 6 & 7 \\
\hline & $\begin{array}{l}\text { Total } \\
\text { tested }\end{array}$ & $\frac{23}{212}=11 \%$ & $\frac{20}{112}=18 \%$ & $\frac{25}{48}=52 \%$ \\
\hline
\end{tabular}

* See legends, Table 4. 
Table 4. Results of mouse foot-pad tests carried out in 23 patients at the start of trial treatment and the outcome of trial treatment

\begin{tabular}{lccccccc}
\hline & & & Total no. & & & & \\
& $\begin{array}{c}\text { No. } \\
\text { tested }\end{array}$ & Sensitive strains & strains & Nft & L & I & F \\
\hline $\begin{array}{l}\text { Clinically } \\
\text { resistant }\end{array}$ & 12 & 1 & 11 & 2 & 3 & 3 & 3 \\
$\begin{array}{l}\text { Responding } \\
\text { to dapsone }\end{array}$ & 11 & 4 & 7 & 2 & 2 & 2 & 1 \\
\hline
\end{tabular}

Nft: 'Not fully titrated': not screened against dapsone $0.01 \%$ but found resistant to one of the lower dapsone concentrations.

L: 'Low-grade resistant': multiplying in mice on dapsone $0.0001 \%$ but not on higher dapsone concentrations.

I: 'Intermediate resistant': multiplying in mice on dapsone $0.001 \%$ but not on a higher dapsone concentration.

F: 'Fully resistant': multiplying in mice on dapsone $0.01 \%$.

proven dapsone-resistant leprosy in the period 1973-77 was, respectively, $3 \cdot 5$ and $1.8 \%$.

The mean duration of treatment with dapsone prior to the relapse in those who proved to be dapsone-resistant was 9.5 years and did not differ from that of the patients in whom the dapsone treatment could be continued.

\section{Discussion}

The following conclusions can be drawn from this study:

(a) Forty-seven percent of the patients presenting with suspected dapsone-resistance and started on trial treatment with full dosage dapsone, proved clinically to be suffering from dapsone-resistant leprosy within the first 3 years of trial treatment. In the following 3 years an additional $8 \%$ stopped responding satisfactorily (Table 2).

(b) The remaining $45 \%$ of the patients continued to respond well to full dosage dapsone for a minimum of 5 years. The initial relapse in these patients was, therefore, apparently caused by a failure of self-medication with dapsone. One should keep this in mind when selecting an alternative regimen for relapsed cases, particularly if this includes rifampicin: the medication should be sufficiently supervised to prevent the emergence of rifampicin-resistant $M$. leprae.

(c) The annual incidence over the period 1973-77 of proven dapsone-resistant leprosy was $1 \cdot 8 \%$ (Table 1 ). This rate is not representative for Ethiopia, because in 
the past great numbers of leprosy patients with social or medical problems moved from the rural areas into Addis Ababa in search of a living or 'better treatment' and this group might, therefore, be quite different as regards duration and regularity of drug intake, frequency of complications, etc., compared to the patients attending a rural clinic.

(d) By the end of 1972, 41 patients were already clinically diagnosed as suffering from dapsone-resistant leprosy. ${ }^{2}$ These, added to the 138 patients discovered between 1973 and 1977, give a known prevalence on 1 January 1978 of 119 per 1000 registered lepromatous cases, which is close to the previously estimated minimum prevalence of 100 per 1000 for that year. ${ }^{4}$

(e) The clinical observations were, to a large extent, in contrast with the results of the MFP tests which were carried out in 43 of the 212 suspected dapsone-resistant patients and which in $86 \%$ demonstrated dapsone resistance (Table 3 ).

This high percentage, as compared with $55 \%$ clinical dapsone resistance, is not explained by the fact that 20 of the 43 tests were carried out at the end of the trial period, when dapsone resistance was already clinically demonstrated. A comparable figure of $78 \%$ was found in the 23 patients in whom the study was done at the intake in the trial. In this group of patients no evidence was shown of a relation between the outcome of trial treatment and the results of the MFP tests (see Table 4). On the contrary, seven of the foot-pad proven dapsone-resistant patients continued to respond to full-dosage dapsone for more than 5 years. They are still bacteriologically negative and clinically quiescent at this time.

The discrepancy between the clinical and laboratory findings may to some extent be explained by the difference in the method used to diagnose dapsoneresistant leprosy. Strains of $M$. leprae capable of multiplying in mice to which dapsone has been administered in a concentration of $0 \cdot 1 \mathrm{mg}$ per $100 \mathrm{~g}$ of food $(0.0001 \%$ in diet $)$, but inhibited by a ten-fold higher concentration, are defined as partially or low-grade resistant.

But a 100-fold higher concentration achieves in mice a dapsone concentration roughly equal to that found in plasma of patients administered $100 \mathrm{mg}$ dapsone daily. A strain found to be partially resistant in the laboratory will, therefore, in man still be inhibited by the now generally accepted daily dosage of $100 \mathrm{mg}$ dapsone and apparently may continue to do so for many years (see Table 2). This strain appears thus, on clinical grounds, to be susceptible to dapsone. It seems, therefore, that the laboratory diagnosis of partial dapsone resistance, which had clinical implications in the era of the low-dosage schedule of dapsone, has lost a great deal of its importance.

The concentration of $10 \mathrm{mg}$ dapsone per $100 \mathrm{~g}$ diet has in the 1960's been considered $^{5,6}$ the demarcation level for testing dapsone resistance: all strains of $M$. leprae multiplying in mice fed $0.03 \%$ or more in their diet were considered dapsone resistant. The assertion in later publications, ${ }^{2,}, 3,6,7$ that patients harbouring bacilli which multiply in mice fed 0.0001 or $0.001 \%$ dapsone in the 
diet would respond for only a few more years to dapsone in full dosage has, to our knowledge, not been supported by hard facts. On the contrary, satisfactory response to dapsone monotherapy for up to 10 years in 11 out of 12 patients with foot-pad evidence of mainly low-grade primary dapsone-resistant leprosy has been reported ${ }^{8,9}$

Current textbooks of microbiology dealing with the interpretation of susceptibility tests in other bacterial diseases take into account the clinical experience with the treatment of the particular type of infection involved. A strain of micro-organisms is defined as resistant to a chemotherapeutic agent, if the strain tested is not completely inhibited by the concentration reached at the site of infection with a dosage within the usual therapeutic range. ${ }^{10,} 11$ This contrasts with the accepted definition of dapsone resistance in $M$. leprae, which only takes into account the MIC as estimated in mouse studies. Leprosy is then defined as dapsone resistant when the causal bacilli multiply in mice receiving $0.0001 \%$ dapsone in the diet, a dosage comparable with an intake of $1 \mathrm{mg}$ dapsone daily in man. ${ }^{2}{ }^{12-14}$ This definition ought to be revised as it has, at the present time, no clinical relevance and is confusing if used interchangeably with the clinical definition of dapsone resistance on which the majority of leprosy programmes have to rely. We, therefore, suggest that only strains multiplying in patients on full dosage dapsone or in mice fed $0.01 \%$ dapsone in the diet, are considered dapsone resistant.

(f) One particular strain of $M$. leprae, multiplying at a dapsone concentration of $0.01 \%$, was obtained from a patient who thereafter responded to dapsone monotherapy for a minimum of 9 years. This might be explained by the presence of a small proportion of fully dapsone-resistant bacilli which multiplied in mice but were possibly killed in the patient by factors other than chemotherapy. In such cases one would expect multiplication in only a proportion of the mice treated with the dapsone $0.01 \%$ diet, but particulars of the test are not available. Repeated histological examinations of the patient showed an upgrading reaction. (g) The duration of dapsone monotherapy in itself does not seem an important determining factor in the emergence of dapsone-resistant strains, because the duration of treatment prior to the relapse was equal in the group of trial patients who proved to be dapsone resistant and the group who continued to respond well to dapsone.

\section{Acknowledgments}

We gratefully acknowledge the major contribution of the MRC Staff at ALERT, in particular Dr J M H Pearson, who designed and initiated this study, carried out most of the mouse foot-pad studies and followed the patients until August 1978. We thank our colleagues at ALERT for their kind cooperation, the registration staff for their patience, and the Armauer Hansen Research Institute for the accommodation of the experimental mice. 


\section{References}

1 Pearson JMH, Ross WF, Rees RJW. DDS resistance in Ethiopia-a progress report. Int J Lepr, 1976; 44: 140-2.

2 Pearson JMH, Cap JA, Haile GS. Dapsone-resistant leprosy and its implications for leprosy control programmes. Lepr Rev, 1977; 48: 83-94.

3 Pearson JMH, Haile GS, Barnetson RStC, Rees RJW. Dapsone-resistant leprosy in Ethiopia. Lepr Rev, 1979; 50: 183-99.

${ }^{4}$ Pearson JMH. The problem of dapsone-resistant leprosy. Int J Lepr, 1981; 49: 417-26.

${ }^{5}$ Pearson JMH. Pettit JHS, Rees RJW. Studies on sulfone resistance in leprosy. 3. A case of 'partial' resistance. Int J Lepr, 1968; 36: 171-8.

${ }^{6}$ Rees RJW. Drug resistance of Mycobacterium leprae, particularly to DDS. Int J Lepr, 1967; 35: 625-36.

7 Pearson JMH, Haile GS, Barnetson RStC, Rees RJW. Dapsone-resistant leprosy in Ethiopia (Letter). Lepr Rev, 1980; 51: 262-3.

8 Jacobson RR, Hastings RC. Primary sulfone resistant leprosy (Abstract). Int J Lepr, 1980; 48: 498.

9 Jacobson RR. Personal communication 1981.

${ }^{10}$ Sherris JC. Laboratory tests in chemotherapy. In Manual of Clinical Microbiology, 2nd ed. Lennette EH, Spaulding EH, Truant JP (eds), Washington D.C.: American Society for Microbiology, 1974, pp. 407-9.

${ }^{11}$ Ericsson HM, Sherris JC. Antibiotic sensitivity testing. Acta Path Microbiol Scand, Sect. B, 1970; 78: 75-6.

12 Shepard CC, Levy L, Fasal P. The sensitivity to dapsone (DDS) of Mycobacterium leprae, from patients with and without previous treatment. Am J Trop Med Hyg, 1969; 18: 258-63.

${ }^{13}$ Hastings RC. Growth of sulfone-resistant $M$. leprae in the foot pads of mice fed dapsone (39976). Proc Soc Exp Biol Med, 1977; 156: 544-5.

14 Pearson JMH, Rees RJW, Waters MFR. Sulphone resistance in leprosy: a review of one hundred proven clinical cases. Lancet, 1975; ii: 69-72. 